\title{
Functional and morphological heterogeneity of emphysema and its implication for selection of patients for lung volume reduction surgery
}

\author{
E.W. Russi*, K.E. Bloch*, W. Weder**
}

\begin{abstract}
Functional and morphological heterogeneity of emphysema and its implication for selection of patients for lung volume reduction surgery. E.W. Russi, K.E. Bloch, W. Weder. (C) ERS Journals Ltd 1999.

ABSTRACT: Lung volume reduction surgery (LVRS) in patients with advanced pulmonary emphysema aims to alleviate symptoms and enhance quality of life by improving respiratory mechanics.

The theoretical concepts of the operation predict the greatest functional benefit in patients with marked hyperinflation, and with airflow obstruction due to loss of elastic recoil.

Consistent observations in several centres, have confirmed these expectations. To achieve maximal reduction in lung volume at the least cost of functional tissue, resection is targeted to the lung zones with the most severe destruction by emphysema, leaving zones with relatively well-preserved tissue intact. Heterogeneity in emphysema distribution as assessed by visual scoring of the chest computed tomography scan according to a simple grading system has been shown to correlate with LVRS outcome variables.

Therefore, evaluation of lung volume reduction surgery candidates has to include the functional and morphological characteristics of the emphysema as well as a general assessment of perioperative risk. However, the knowledge of potential predictive factors of lung volume reduction surgery outcome is so far based on retrospective analysis of highly selected patients. Therefore, many questions in respect of the selection of ideal candidates for this procedure remain unanswered at the present time.
\end{abstract}

Eur Respir J 1999; 14: 230-236.

*Pulmonary Division and **Division of Thoracic Surgery, University Hospital, Zürich, Switzerland.

Correspondence: EW Russi

Pulmonary Division

University Hospital

Rämistr. 100

CH-8091 Zürich

Switzerland

Fax: 4112554451

Keywords: Emphysema

emphysema morphology

lung volume reduction surgery

outcome

Received: June 101999

Accepted after revision June 171999

This work was supported by grants from the Swiss National Foundation (3200043358; 95/1) and the Zürich Lung League.
There is little doubt, that lung volume reduction surgery (LVRS) has the potential to improve lung function, exercise tolerance, shortness of breath and health-related quality of life in many carefully selected patients with severe emphysema. The degree of improvement in these parameters exceeds that of a placebo effect and the efficacy of comprehensive pulmonary rehabilitation [1-8]. The mechanisms by which these beneficial effects are achieved are primarily related to improvements in respiratory mechanics, whereas improvements in gas exchange, in particular in arterial oxygenation, are only minimal and presumably not clinically relevant in the majority of patients $[7,9]$.

From several recent studies on the long-term effects of LVRS [10-13], it has become obvious that the improvement in lung mechanics peaks at 3-6 months after surgery and declines steadily thereafter. Despite this, in the majority of patients, significant and clinically relevant improvements are maintained for $\geq 2$ yrs after surgery. Insufficient data are currently available regarding the long-term survival of patients after LVRS. Owing to the specific selection for surgery, which excludes patients with relevant comorbid conditions, e.g. coronary artery heart disease, etc., comparisons with historical controls are not appropriate. Until this gap in the knowledge is closed, it seems prudent to consider LVRS as a palliative therapy that should be performed only in patients who are severely symptomatic.

Functional improvement after LVRS is observed in the majority of patients selected according to empirically developed guidelines $[14,15]$. The selection criteria are based on sound physiological assumptions and inferred

Previous articles in this series: No. 1. E. Marchand, G. Gayan-Ramirez, P. De Leyn, M. Decramer. Physiological basis of improvement after lung volume reduction surgery for severe emphysema: where are we? Eur Respir J 1999; 13: 686-696. No. 2. W. Klepetko. Surgical aspects and techniques of lung volume reduction surgery for severe emphysema. Eur Respir J 1999; 13: 919-925. No. 3. H. Teschler, A.B. Thompson, G. Stamatis. Short- and long-term functional results after lung volume reduction surgery for severe emphysema. Eur Respir J 1999; 13: 1170-1176. 
from retrospective analyses of correlations between various preoperative patient characteristics and functional outcome. Despite adherence to a relatively stringent selection procedure that assures a favourable risk:benefit ratio for LVRS in general, the amount of functional improvement varies widely among individuals, and, in some patients, no gain or even a loss in pulmonary function has been observed after the operation.

In order to achieve more consistent improvement after LVRS, it is crucial to identify the factors that determine outcome and optimize the selection of candidates for the procedure accordingly. To address these points, various factors that have been proposed as relevant to the effects of LVRS based on theoretical concepts and clinical experience are reviewed here. The anatomical aspects of different emphysema types, along with clinical and functional characteristics, will be outlined in order to subsequently discuss the implications of morphological emphysema heterogeneity in relation to functional and other characteristics on outcome after LVRS.

\section{Emphysema, a complex and heterogeneous lung disease}

Emphysema is defined as abnormal enlargement of the airspaces distal to the terminal bronchioles, accompanied by destruction of their walls, and without obvious fibrosis [16]. Chronic bronchitis, on the other hand, is a disease of the large airways characterized by bronchial gland enlargement, and is often accompanied by bronchiolitis, an inflammation of the small airways leading to their narrowing and eventual obstruction. In an individual patient with chronic obstructive pulmonary disease (COPD), these three morphological components generally coexist to varying degrees and contribute distinctively to the abnormalities in lung and chest wall mechanics, gas exchange and pulmonary circulation. In addition, other factors such as the patient's constitution, nutritional status and immune responsiveness as well as genetically codetermined properties such as the control of breathing and $\alpha_{1}$-antitrypsin deficiency, modify the clinical presentation and functional features of COPD. Approximately $10 \%$ of patients with COPD also have clinical features of asthma. Other patients are prone to recurrent bronchopulmonary infection. They produce copious amounts of sputum and experience repeated exacerbations. In still other patients, more or less conspicuous tubular bronchiectases can be detected by means of high-resolution computed tomography (CT). Although the predominant clinical features of intrinsic airways disease are commonly regarded as an exclusion criterion for LVRS, the impact of such aspects on the outcome of surgery has not been systematically studied. The impact of $\alpha_{1}$-antitrypsin deficiency on the outcome of LVRS has recently been studied. CASSINA et al. [17] found similar initial improvements after LVRS in patients with this hereditary disorder compared to smokers with emphysema. The pulmonary function declined much faster in the $\alpha_{1}$-antitrypsin group than in the group with smoker's emphysema. However, their findings could not be confirmed in a smaller group of patients [18].
Severe COPD is almost always accompanied by emphysema. Three different types of emphysema can be recognized, at least when the disease is not in too advanced a state. 1) Centriacinar emphysema begins in the respiratory bronchioles and spreads peripherally. This type of emphysema is associated with longstanding cigarette smoking and predominantly involves the upper lung zones. 2) Panacinar emphysema involves the entire acinus uniformly and predominates in the lower zones of the lungs. This form of emphysema is generally seen in patients with homozygous $\alpha_{1}$-antitrypsin deficiency but often occurs in association with centriacinar emphysema in smokers without this proteinase inhibitor deficiency. 3) Distal acinar emphysema, also known as paraseptal emphysema, predominantly involves alveolar ducts and sacs, the distal portion of the acinus. The lesions tend to occur adjacent to the fibrous septa or the pleura and may lead to spontaneous pneumothorax. An additional distinct form of emphysema, bullous disease of the lung, is characterized by large and eventually growing bullae, which may compress adjacent relatively uninvolved lung.

In many patients, combinations of these various forms of emphysema coexist. Furthermore, from a surgical point of view and with respect to the volume reduction procedure, this anatomical classification is of secondary usefulness and has been superceded by morphological categories, which take into greater consideration the localization, distribution and degree of emphysema as assessed by CT.

\section{Role of functional evaluation in prediction of lung volume reduction surgery outcome}

Pivotal to the surgical concept of LVRS are the distinctive functional consequences of pulmonary emphysema, i.e. loss of lung elasticity accompanied by a reduction in airway calibre and pulmonary hyperinflation with concomitant impairment of respiratory muscle function. LVRS aims to improve ventilation by restoring the pulmonary elastic recoil and reducing the size of the hyperinflated lung. However, the exact mechanisms underlying the improvement in lung mechanics and respiratory muscle function are still incompletely understood [19]. It remains unclear which of the two above-mentioned features are most closely linked with a favourable functional outcome $[20,21]$.

BRANTIGAN et al. [22] originally proposed that, in emphysema, increasing elastic recoil by multiple wedge resections decreases obstruction to airflow by means of airway tethering. Several years later, measurements of elastic recoil before and after LVRS supported these assumptions. In 20 patients undergoing LVRS, 16 experienced an increase in elastic recoil [23]. These patients experienced a significantly greater improvement in exercise capacity than the four in whom elastic recoil did not change.

According to this same concept, patients with obstruction due to intrinsic airway disease would not benefit as much from LVRS. This hypothesis was tested by INGENITO et al. [24]. Based on the assumption that markedly elevated inspiratory resistance may be the functional hallmark of a relevant component of intrinsic airway disease, 
they measured lung resistance during inspiration. During expiration, resistance to airflow in patients with emphysema is limited by airway collapse due to positive intrathoracic pressure. During inspiration, intrathoracic pressure is subatmospheric, tending to pull airways open; thus, dynamic collapse does not occur [25]. In theory, lung resistance measured during inspiration should discriminate between patients with airflow obstruction primarily as a result of parenchymal tissue destruction, decreased lung elastic recoil, and loss of airway tethering and those who also have significant intrinsic airway disease related to airway narrowing, mucous plugging and obstruction of the airways [26]. INGENITO et al. [24] studied two groups of patients with similar preoperative forced expiratory volume in one second (FEV1), forced vital capacity (FVC), total lung capacity (TLC), and residual volume (RV), but different inspiratory airway resistance. Univariate analysis and multivariate regression showed that only preoperative inspiratory airway resistance was significantly correlated with the postoperative change in FEV1. However, this study may have been hampered by the fact that TLC and RV were measured by means of helium-dilution, and, therefore, pulmonary hyperinflation and its role may have been underestimated.

Recently, Fessler and Permutt [27] emphasized the importance of the decrease in vital capacity (VC) as a consequence of hyperinflation as one of the major mechanisms of impairment in respiratory mechanics and symptoms in severe COPD. Their theoretical model predicts that LVRS should improve flow limitation primarily by improving the match between the size of the lungs and the ribcage. This is achieved by decreasing RV more than TLC and thus achieving a gain in VC. Based on certain theoretical assumptions FessLer and PeRMUTt [27] anticipated that the effect of LVRS on the direction and magnitude of the change in $\mathrm{VC}$ would be dominated by RV/TLC. A maximal gain in VC and FEV1 after surgery would be expected in LVRS candidates with the highest $\mathrm{RV} / \mathrm{TLC}$. In their view, the measurement of elastic recoil pressure determines neither the best candidates nor the mechanisms of their improvement after LVRS. Supporting these predictions, a major increase in VC after LVRS has been reported by several groups, and the gain in FEV1 after LVRS was correlated with the degree of reduction in RV/TLC [3, 14, 28-30].

Hypercapnia often complicates severe COPD, and was associated with increased mortality in early studies [31]. Some authors have been reluctant to operate on patients with more than mild elevation of their arterial carbon dioxide tension $\left(\mathrm{Pa}_{\mathrm{a}} \mathrm{CO}_{2}\right)$ since they expected increased perioperative mortality in these severely ill patients $[3$, 32-34]. Others have been less concerned and found neither an increase in perioperative mortality nor inferior functional results [35-38]. In another study, only a minor increase in mean arterial oxygen tension $\left(\mathrm{Pa}_{\mathrm{a}} \mathrm{O}_{2}\right)$ and a concomitant small drop in $\mathrm{Pa}, \mathrm{CO}_{2}$ were observed up to 6 months after surgery [7]. Based on this experience and a review of the literature, it was concluded that gas exchange remained essentially unchanged in most patients after LVRS. Therefore, this operation should not be offered with the promise that blood gas levels will be improved, and, conversely, impaired gas exchange in can- didates for LVRS per se does not exclude successful surgery.

These observations of no relevant changes in arterial blood gas levels after LVRS are supported by the finding that the diffusing capacity of the lung for carbon monoxide $(D \mathrm{~L}, \mathrm{CO})$ is not improved by surgery. The degree of reduction in DL,CO reflects the severity of emphysema, and an extremely low $D$ L,CO $(<20 \%$ of the predicted value $)$ is suggestive of such an extensive destruction of lung tissue, so called vanishing lung, that LVRS is no longer an option.

One of the long-term sequelae of LVRS that has been of concern is the development or worsening of pulmonary arterial hypertension due to reduction of the vascular bed. A mean pulmonary artery pressure (PAPmean) of $>35$ $\mathrm{mmHg}$ is regarded as reflecting considerably impaired pulmonary vascular reserve, and is, therefore, a contraindication for LVRS [14]. It has been documented, however, that in patients with no or only mild pulmonary hypertension, PAPmean at rest remains unaltered [39], and the commonly observed mild exercise-induced pulmonary hypertension does not worsen after LVRS [40, 41]. Therefore, the authors do not routinely perform an invasive evaluation of pulmonary haemodynamics before LVRS.

\section{Role of preoperative imaging in the prediction of lung volume reduction surgery outcome}

In addition to functional characteristics, emphysema of such a severity that LVRS is considered a therapeutic option may be diagnosed by chest radiography. The most reliable method of obtaining information on the degree and distribution of emphysema is chest CT scanning. Highresolution $\mathrm{CT}$ imaging is the most sensitive technique for detecting pulmonary emphysema and relevant bronchial disease, i.e. bronchiectases. Spiral CT serves to detect pulmonary nodules, since this patient population is at high risk for occult bronchogenic carcinoma, which can be detected in a relevant number of candidates for LVRS [42].

The notion that LVRS would be particularly beneficial in patients with a heterogeneous distribution of emphysematous destruction, i.e. with large bullae and areas that are relatively well preserved, is based on earlier experience with bullectomy. Radiographic imaging has been used to assess the location and amount of bullous destruction. For more than four decades, surgery has been successfully used to improve lung function in patients with giant bullous emphysema. Patients with bullae larger than one-third of a hemithorax and an FEV1 of $<50 \%$ pred seemed to benefit the most [43]. The improvements in pulmonary function were assumed to result from decompression of adjacent lung tissue by means of the removal of large spaceoccupying bullae [44]. Many centres performing bullectomy, either unilaterally or bilaterally, have the same experience, with usually spectacular functional improvements. However, the prevalence of this type of emphysema is rather low.

Many groups, including COOPER et al. [14], who pioneered the modern concept of LVRS, preferentially select patients with marked heterogeneity in the severity of emphysema in their lungs, i.e. with distinct areas of destroyed parenchyma as well as relatively well-preserved lung tissue. They argue that those parts of the lung 
a)

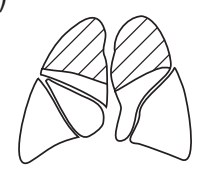

b)

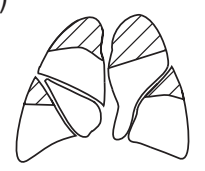

c)

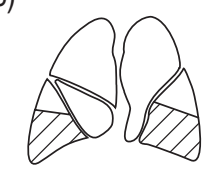

d)

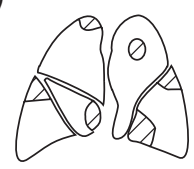

e)

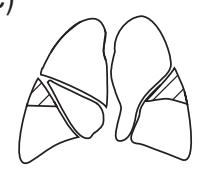

f)

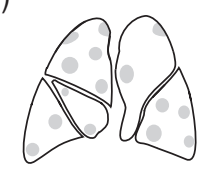

g)

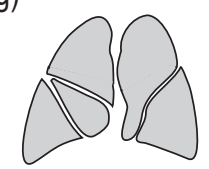

Fig. 1. - A simple surgically oriented grading system for emphysema heterogeneity has been proposed based on visual scoring of chest computed tomography images. Three major types of emphysema distribution were defined: markedly heterogeneous: a) upper lobe; b) upper lobe and apical segment (lower lobe); and c) lower lobe (basal segment), intermediately heterogeneous: d) anatomically indistinct; and e) anatomically distinct, and homogeneous: f) with patchy areas; and g) completely homogeneous. (From [46].)

that are most severely affected, as assessed by CT and perfusion scan of the lung, should be chosen as target areas for resection. SLONE and GiERADA [45] showed good correlations between certain aspects of morphology and functional outcome. They based their analysis on a sophisticated classification system of emphysema morphology considering specific aspects of LVRS. Favourable radiological features included marked heterogeneity of emphysema, particularly upper lobe predominance accompanied by mildly affected lung areas and the presence of compressed lung.

A simplified surgically oriented classification system based on CT findings has been proposed (fig. 1). It distinguishes between homogeneous, moderately heterogeneous and markedly heterogeneous emphysema distribution, and considers the predominance of the involved lobes [46]. Fair interobserver agreement was found on application of this classification system. Functional improvement after LVRS was greatest in markedly heterogeneous emphysema, with a mean increase in FEV1 of $81 \%$ compared with $44 \%$ for intermediately heterogeneous and $34 \%$ for homogeneous emphysema (fig. 2). However, the degree of individual gain varied greatly. Furthermore, regression analysis revealed that $78 \%$ of the variation in postoperative gain in FEV1 could not be explained by preoperative characteristics of pulmonary function or chest CT morphology [46].

Wisser et al. [47] studied the relation between morphological grading of emphysema and improvement after LVRS. The morphology of emphysema was quantified using standard chest radiographs and CT imaging on the basis of four variables: degree of hyperinflation, de- gree of impairment in diaphragmatic mechanics, degree of heterogeneity and severity of parenchymal destruction. The degree of heterogeneity was significantly correlated with functional improvement in terms of FEV1. The severity of parenchymal destruction was significantly associated with 30-day mortality.

\section{Comprehensive concept for assessment of lung volume reduction surgery candidates}

To separately assess the relative contribution of various functional and morphological characteristics of emphysema in LVRS candidates to surgical outcome, 3-month postoperative data from 70 patients after video-assisted thoracoscopic LVRS was analysed [8]. Based on theoretical considerations [27] and previous experience [46], the hypothesis that each of the 3 factors, 1) mechanical impairment in terms of hyperinflation/airflow obstruction, 2) emphysema severity as assessed by impairment in diffusing capacity, and 3) degree of heterogeneity of distribution of emphysematous destruction estimated by CT radiological classification [46], had a significant impact on functional improvement was tested. By carefully matching patients according to two of these three factors and contrasting them with regard to the third, and by multiple regression analysis, evidence for all of these three assumptions was found. The weight of the individual and combined factors was relatively low, however. By using preoperative FEV1, RV/TLC, DL,CO, chest CT and perfusion scintigraphic heterogeneity scores as the independent and FVC, RV/TLC, and FEV1 as dependent variables, coefficients of multiple correlations of 0.68 ,
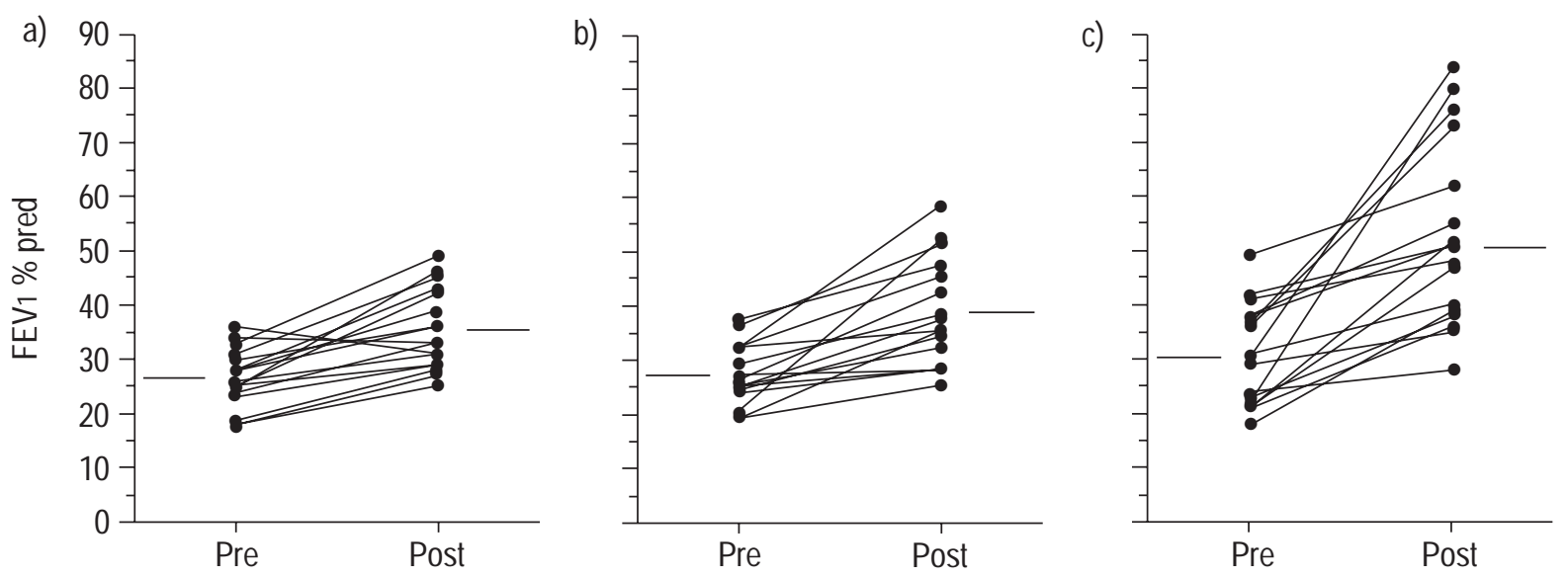

Fig. 2. - The effect of thoracoscopic lung volume reduction on forced expiratory volume in one second (FEV1) was studied in three groups with similar lung function at baseline but with various degrees of emphysema heterogeneity before (Pre) and 3 months after lung volume reduction surgery (Post): a) homogeneous $(n=17, p=0.01)$; b) intermediately heterogeneous $(n=16, p=0.001)$; and $c)$ markedly heterogeneous ( $=18$, $p=0.0002)$. The gain in FEV1 was more pronounced in c) than in b), but even in a) significant functional improvements were achieved. Horizontal bars represent means. (From [46].) 
0.64 and 0.51 for changes in FVC, RV/TLC and FEV1 as a result of LVRS, respectively, were found. Approximately half $(46 \%)$ of the variability in these outcome measures was explained by the model. To improve prediction of surgical outcome on the basis of individual LVRS candidates, receiver operating characteristic curves that provide sensitivities and specificities for a given improvement in outcome variables were constructed. For example, the specificity was $95 \%$ for predicting a gain in FEV1 $>0.3 \mathrm{~L}$, and in FVC of $>1 \mathrm{~L}$, on the basis of a preoperative visual analogue chest CT heterogeneity score of $>95 \%$, a perfusion scintigraphic heterogeneity score, of $92 \%$, an RV/TLC ratio of $>0.77$ and a $D$ L,CO of $<27 \%$ pred (fig. 3). However, patients with such severe functional compromise due to emphysema, and, at the same time, heterogeneous distribution of lung destruction are relatively uncommon. The specificity of the prediction of LVRS outcome is therefore often much lower.

There are other reasons that explain the difficulties in selecting patients for LVRS. Data from several studies confirm that factors not assessed by conventional pul-
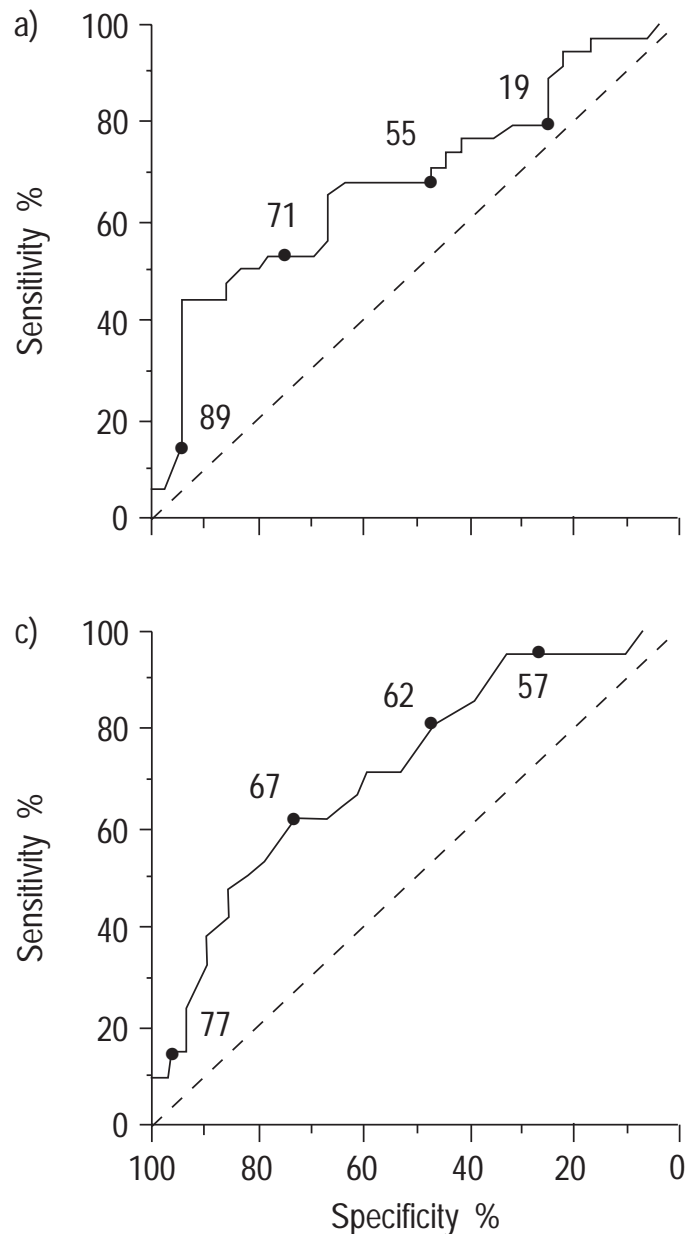

monary function tests or CT radiography are relevant to surgical outcome [28, 48]. Many of these factors have so far not been identified, but it is obvious that the amount of reduced lung volume, the selection of target areas for resection and the surgical technique used are major determinants of outcome.

A major obstacle to the study of correlations between physiological outcomes and preoperative parameters is the lack of accurate information on the amount of lung tissue excised by the surgeon. In other words, the "dosage of surgery" is ill defined. The goal of the operation is to remove $20-30 \%$ of the lung volume, preferably targeting the regions of most severe emphysema and preserving lung tissue that is less severely diseased. This fraction is generally only roughly estimated from inspection of the removed pieces of partially atelectatic lung at the time of surgery. Weighing of resected specimens is meaningless since the volume and density of resected and unresected lung in situ is not known. The importance of the amount of reduced lung volume is not only theoretically sound but corroborated by analysis of LVRS data. By including a

b)

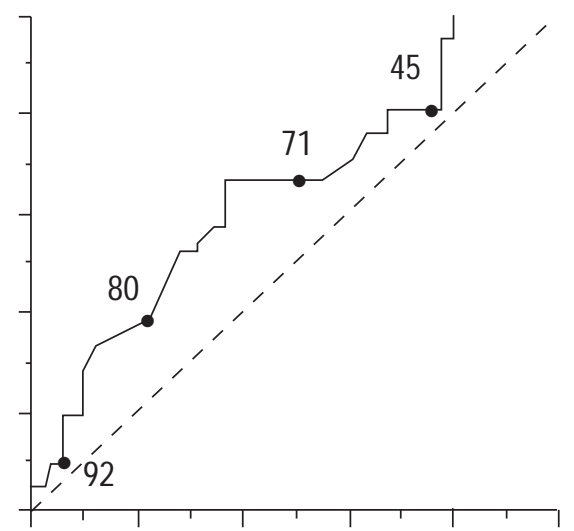

d)

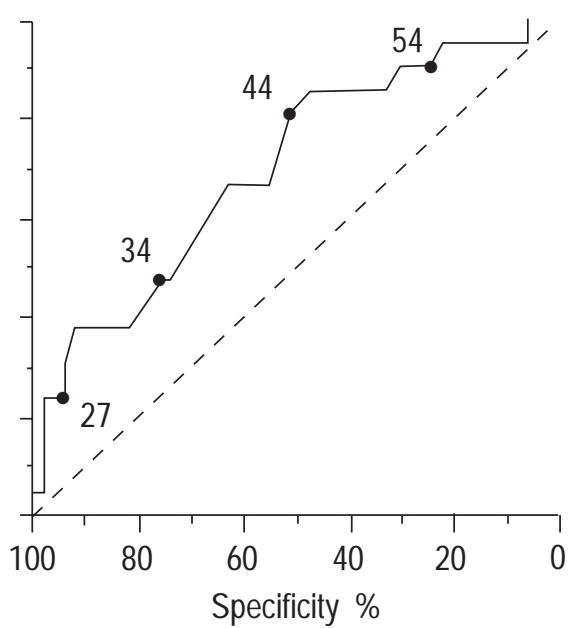

Fig. 3. - Receiver operating characteristic curves (ROC) were derived by analysis of preoperative characteristics and outcome of 70 patients after thoracosopic lung volume reduction surgery (LVRS). They depict the sensitivities and specificities for experiencing a predefined gain in an LVRS outcome measure at various cut-off points of the preoperative variables. This may help in the assessment of a surgical candidate on an individual basis. ROC curves for: a) the criterion "gain in forced expiratory volume in one second (FEV1) $>0.3$ L" for chest computed tomography visual analogue heterogeneity scores (area under the curve (AUC) \pm SEM $0.68 \pm 0.06$ ); b) the criterion "gain in forced vital capacity (FVC) $>1$ L" for scintigraphic visual analogue heterogeneity scores (AUC $0.64 \pm 0.07$ ); c) "gain in FVC $>1$ L" for residual volume/total lung capacity (AUC $0.72 \pm 0.07$ ); and d) "gain in FVC $>1 \mathrm{~L}$ " for diffusing capacity of the lung for carbon monoxide (AUC $0.70 \pm 0.06$ ). AUC were all $>0.5$, the value achieved by chance ( $<<0.05$ ). The cut-off levels for each variable corresponding to $25,50,75$ and $95 \%$ specificity are labelled (\%). (Redrawn from [8].) 
recently proposed measure of the amount of resected lung volume in situ, the fractional reduction in residual volume (1-RV after surgery/RV before surgery) [27], into the above-described model for prediction of outcome after LVRS, predictive accuracy was significantly improved [8].

Another finding of note is the positive correlation of emphysema heterogeneity scores with the surrogate measure of resected lung volume in situ [8]. This indicates that a surgeon may be influenced in his operative technique by preoperative findings in that he might be less reluctant to resect a relatively large amount of lung tissue in patients with distinctly heterogeneous emphysema, but remove less tissue in patients with a homogeneous emphysema.

Common to all analyses of predictive factors for LVRS is that they have been performed retrospectively in highly preselected patients. Therefore, conclusions based on these data should be interpreted cautiously.

\section{Conclusion}

The rapidly growing experience with lung volume reduction surgery has demonstrated convincingly that this novel surgical treatment modality is a valuable option in highly selected patients with advanced pulmonary emphysema. In experienced hands, the perioperative mortality of this procedure is $<5 \%$. Evaluation of lung volume reduction surgery candidates should include functional and morphological characteristics of the emphysema as well as a general internal medical assessment of perioperative risk. Major obstacles in the interpretation of published studies on selection criteria comprise its retrospective nature and the inability to accurately quantify the amount of resected emphysematous lung tissue. Future investigations should be directed at improving identification of the patients with the highest risk:benefit ratio for this operation.

\section{References}

1. Cooper JD, Lefrak SS. Lung-reduction surgery: 5 years on. Lancet 1999; 353: (Suppl. 1): 26-27.

2. Bingisser R, Zollinger A, Hauser M, Bloch KE, Russi $\mathrm{EW}$, Weder W. Bilateral volume reduction surgery for diffuse pulmonary emphysema by video-assisted thoracoscopy. J Thorac Cardiovasc Surg 1996; 112: 875-882.

3. McKenna RJ Jr., Brenner M, Gelb AF, et al. A randomized, prospective trial of stapled lung reduction versus laser bullectomy for diffuse emphysema. $J$ Thorac Cardiovasc Surg 1996; 111: 317-322.

4. Keller CA, Ruppel G, Hibbet A, Osterloh J, Naunheim KS. Thoracoscopic lung volume reduction surgery reduces dyspnea and improves exercise capacity in patients with emphysema. Am J Respir Crit Care Med 1997; 156: 60-67.

5. Tschernko EM, Wisser W, Wanke T, et al. Changes in ventilatory mechanics and diaphragmatic function after lung volume reduction surgery in patients with COPD. Thorax 1997; 52: 545-550.

6. Teschler H, Stamatis G, El-Raouf Farhat AA, Meyer FJ, Costabel U, Konietzko N. Effect of surgical lung volume reduction on respiratory muscle function in pulmonary emphysema. Eur Respir J 1996; 9: 1779-1784.

7. Stammberger U, Bloch KE, Thurnheer R, Weder W, Russi EW. Exercise performance and gas exchange after bilat- eral video-assisted thoracoscopic lung volume reduction for severe emphysema. Eur Respir J 1998; 12: 785-792.

8. Thurnheer R, Engel H, Weder W, et al. Role of lung perfusion scintrigraphy in relation to chest computed tomography and pulmonary function in the evaluation of candidates for lung volume reduction surgery. $\mathrm{Am} \mathrm{J}$ Respir Crit Care Med 1999; 159: 301-310.

9. Albert RK, Benditt JO, Hildebrandt J, Wood DE, Hlastala MP. Lung volume reduction surgery has variable effects on blood gases in patients with emphysema. Am J Respir Crit Care Med 1998; 158: 71-76.

10. Gelb AF, Brenner M, McKenna RJ Jr., Fischel R, Zamel $\mathrm{N}$, Schein MJ. Serial lung function and elastic recoil 2 years after lung volume reduction surgery for emphysema. Chest 1998; 113: 1497-1506.

11. Stammberger U, Thurnheer R, Bloch KE, Laube I, Weder W, Russi EW. Long term functional results after bilateral thoracoscopic lung volume reduction surgery. Am J Respir Crit Care Med 1998; 157: A336.

12. Yusen RD, Pohl MS, Richardson V, et al. 3-Year results after lung volume reduction surgery. Am J Respir Crit Care Med 1998; 157: A335.

13. Brenner M, McKenna RJJ, Chen JC, et al. Survival following bilateral staple lung volume reduction surgery for emphysema. Chest 1999; 115: 390-396.

14. Cooper JD, Trulock EP, Triantafillou AN, et al. Bilateral pneumectomy (volume reduction) for chronic obstructive pulmonary disease. J Thorac Cardiovasc Surg 1995; 109: $106-119$.

15. Russi EW, Stammberger U, Weder W. Lung volume reduction surgery for emphysema. Eur Respir J 1997; 19: 208-218.

16. Snider GL, Kleinerman J, Thurlbeck WM, Bengali ZH. The definition of emphysema: report of a national heart and blood institute, division of lung diseases, workshop. Am Rev Respir Dis 1985; 132: 182-185.

17. Cassina PC, Teschler H, Konietzko N, Theegarten D, Stamatis G. Two year results after lung volume reduction surgery in alphal-antitrypsin deficiency versus smoker's emphysema. Eur Respir J 1998; 12: 1028-1032.

18. Ritscher D, Hamacher J, Weder W, Russi EW. Lung volume reduction surgery in patients with $\alpha-1$ antitrypsin deficiency and emphysema. Schweiz Med Woehenschr 1999; 129: (Suppl. 107): 16S.

19. Marchand E, Gayan-Ramirez G, De Leyn P, Decramer M. Physiological basis of improvement after lung volume reduction surgery for severe emphysema: where are we? Eur Respir J 1999; 13: 686-696.

20. Hoppin FG Jr.. Theoretical basis for improvement following reduction pneumoplasty in emphysema. Am $J$ Respir Crit Care Med 1997; 155: 520-525.

21. Fessler HE, Wise RA. Lung volume reduction surgery. Is less really more? Am J Respir Crit Care Med 1999; 159: 1031-1035.

22. Brantigan OC, Mueller EA, Kress MB. A surgical approach to pulmonary emphysema. Am Rev Respir Dis 1959; 80: 194-202.

23. Sciurba FC, Rogers RM, Keenan RJ, et al. Improvement in pulmonary function and elastic recoil after lung-reduction surgery for diffuse emphysema. $N$ Engl $J$ Med 1996; 334: 1095-1099.

24. Ingenito EP, Evans RB, Loring SH, et al. Relation between preoperative inspiratory lung resistance and the outcome of lung-volume-reduction surgery for emphysema. N Engl J Med 1998; 338: 1181-1185.

25. Hyatt R. The interrelationships of pressure, flow, and volume during various respiratory maneuvers in normal 
and emphysematous subjects. Am Rev Respir Dis 1961; 83: 676-683.

26. Leaver DG, Tattersfield AE, Pride NB. Contribution of loss of lung recoil and of enhanced airways collapsibility to the airflow obstruction of chronic bronchitis and emphysema. J Clin Invest 1973; 52: 2117-2128.

27. Fessler HE, Permutt S. Lung volume reduction surgery and airflow limitation. Am J Respir Crit Care Med 1998; 157: 715-722.

28. Brenner M, McKenna RJ Jr., Gelb AF, et al. Objective predictors of response for staple versus laser emphysematous lung reduction. Am J Respir Crit Care Med 1997; 155: 1295-1301.

29. Gelb AF, McKenna RJ Jr., Brenner M, Fischel RJ, Baydur A, Zamel N. Contribution of lung and chest wall mechanics following emphysema resection. Chest 1996; 110: 11-17.

30. Stammberger U, Thurnheer R, Bloch KE, et al. Thoracoscopic bilateral lung volume reduction for diffuse pulmonary emphysema. Eur J Cardiothorac Surg 1997; 11: 1005-1010.

31. Boushy SF, Coates EO Jr. The prognostic value of pulmonary function tests in emphysema, with special reference to arterial blood studies. Am Rev Respir Dis 1964; 90: 553-563.

32. Cooper JD, Patterson GA, Sundaresan RS, et al. Results of 150 consecutive bilateral lung volume reduction procedures in patients with severe emphysema. J Thorac Cardiovasc Surg 1996; 112: 1319-1330.

33. Gaissert HA, Trulock EP, Cooper JD, Sundaresan RS, Patterson GA. Comparison of early functional results after volume reduction or lung transplantation for chronic obstructive pulmonary disease. J Thorac Cardiovasc Surg 1996; 111: 296-305.

34. Miller JI Jr., Lee RB, Mansour KA. Lung volume reduction surgery: lessons learned. Ann Thorac Surg 1996; 61: 1464-1469.

35. Argenziano M, Moazami N, Thomashow B, et al. Extended indications for lung volume reduction surgery in advanced emphysema. Ann Thorac Surg 1996; 62: 1588-1597.

36. Criner GJ, O'Brien GO, Furukawa S, et al. Lung volume reduction surgery in ventilator-dependent COPD patients. Chest 1996; 110: 877-884.

37. O'Brien GM, Furukawa S, Kuzma AM, Cordova F, Criner
GJ. Improvements in lung function, exercise, and quality of life in hypercapnic COPD patients after lung volume reduction surgery. Chest 1999; 115: 75-84.

38. Wisser W, Klepetko W, Senbaklavaci O, et al. Chronic hypercapnia should not exclude patients from lung volume reduction surgery. Eur J Cardiothorac Surg 1998; 14: 107-112.

39. Thurnheer R, Bingisser R, Stammberger U, et al. Effect of lung volume reduction surgery on pulmonary hemodynamics in severe pulmonary emphysema. Eur J Cardiothorac Surg 1998; 13: 253-258.

40. Kubo K, Koizumi T, Fujimoto K, Matsuzawa Y, Haniuda $\mathrm{M}$, Takahashi H. Effects of lung volume reduction surgery on exercise pulmonary hemodynarnics in severe emphysema. Chest 1998; 114: 1575-1582.

41. Oswald-Mammosser M, Kessler R, Massard G, Wihlm JM, Weitzenblum E, Lonsdorfer J. Effect of lung volume reduction surgery on gas exchange and pulmonary hemodynamics at rest and during exercise. Am J Respir Crit Care Med 1999; 158: 1020-1025.

42. Pigula FA, Keenan RJ, Ferson PF, Landreneau RJ. Unsuspected lung cancer found in work-up for lung reduction operation. Ann Thorac Surg 1996; 61: 174-176.

43. Gaensler EA, Cugell DW, Knudson RJ, FitzGerald MX. Surgical management of emphysema. Clin Chest Med 1983; 4: 443-463.

44. Connolly JE, Wilson AF. The current status of surgery for bullous emphysema. J Thorac Cardiovasc Surg 1989; 97 : 351-361.

45. Slone RM, Gierada DS. Radiology of pulmonary emphysema and lung volume reduction surgery. Semin Thorac Cardiovasc Surg 1996; 8: 61-82.

46. Weder W, Thurnheer R, Stammberger U, Bürge M, Russi EW, Bloch KE. Radiological emphysema morphology is associated with outcome after surgical lung volume reduction. Ann Thorac Surg 1997; 64: 313-320.

47. Wisser W, Klepetko W, Kontrus M, et al. Morphologic grading of the emphysematous lung and its relation to improvement after lung volume reduction surgery. Ann Thorac Surg 1998; 65: 793-799.

48. Bloch KE, Li Y, Zhang J, Bingisser R, Kaplan V, Russi EW. Effect of surgical lung volume reduction on breathing patterns in severe pulmonary emphysema. $\mathrm{Am} \mathrm{J}$ Respir Crit Care Med 1997; 156: 553-560. 